B. BOUGIE ${ }^{1,2}$

M. TULEJ ${ }^{1}$

T. DREIER ${ }^{1, \infty}$

N.J. DAM ${ }^{2}$

J.J. TER MEULEN ${ }^{2}$

T. GERBER ${ }^{1}$

\title{
Optical diagnostics of diesel spray injections and combustion in a high-pressure high-temperature cell
}

\author{
${ }^{1}$ Reaction Analysis Group, Department of General Energy, Paul Scherrer Institute, \\ CH-5232 Villigen PSI, Switzerland \\ ${ }^{2}$ Radboud University Nijmegen, Institute for Molecules and Materials, Applied Physics, Toernooiveld 1, \\ 6525 ED Nijmegen, The Netherlands
}

\section{Received: 3 December 2004 /}

Revised version: 16 March 2005

Published online: 3 June 2005 • ( ) Springer-Verlag 2005

ABSTRACT We report on spatially and temporally resolved optical diagnostic measurements of propagation and combustion of diesel sprays introduced through a single-hole fuel injector into a constant volume, high-temperature, highpressure cell. From shadowgraphy images in non-reacting environments of pure nitrogen, penetration lengths and dispersion angles were determined for non-vaporizing and vaporizing conditions, and found to be in reasonable agreement with standard models for liquid jet propagation and break-up.

Quasi-simultaneous two-dimensional images were obtained of laser elastic light scattering, shadowgraphs and spectrally integrated flame emission in a reacting environment (cell temperature $850 \mathrm{~K}$ ). In addition laser-induced incandescence was employed for the identification of soot-loaded regions. The simultaneously recorded spray images exhibit remarkable structural similarity and provide complementary information about the spray propagation and combustion process. The measurements also reveal the fuel vapor cloud extending well beyond the liquid core and close to the nozzle tip. Ignition takes place close to the tip of the spray within the mixing layer of fuel vapor and surrounding air. Soot is formed in the vapor core region at the tip of the liquid fuel jet. Our results support recently developed phenomenological model on diesel spray combustion.

PACS 42.62.Cf; 42.62.Fi; 82.33.Vx

1

\section{Introduction}

Because of their efficiency diesel engines offer great advantages in comparison with other internal combustion concepts for purposes of transportation. However, due to increasingly stringent exhaust gas legislation, aimed at reducing environmental and health concerns (notably involving soot and $\mathrm{NO}_{\mathrm{x}}$ ), a deeper understanding of the physico-chemical

Fax: +41-56-310-2199, E-mail: thomas.dreier@psi.ch mechanisms of diesel combustion processes is mandatory. Essential features of the combustion process of a diesel fuel spray, such as vaporization, ignition and soot formation, have therefore to be identified for wide ranges of operating conditions.

In diesel engines spray evolution is strongly influenced by fuel injector design and characteristics (nozzle geometry, injection pressure, etc.) and ambient conditions in the combustion chamber (temperature, pressure, turbulence intensity, etc.). This concerns the propagation and dispersion of a high-speed liquid fuel jet into a mostly turbulent high density gaseous environment, its break-up into droplets, vaporization and ignition. On their turn these processes affect the subsequent combustion, soot formation and exhaust gas emission. Since in practice these phenomena are highly unsteady, the unravelling of correlations between different scalars necessitates simultaneous observation of as many parameters as possible during one single spray injection event. Consequently, optical techniques constitute a useful tool for in situ diagnostics of these processes with high temporal and spatial resolution. Combustion strategies for the reduction of soot and toxic emissions in diesel engines might also benefit from such in situ observation of mutual dependencies between reactive and non-reactive scalars. Besides gaining a deeper understanding of, e.g., soot/flame interactions during the combustion process, multi-scalar imaging will help in the validation of existing spray propagation models $[1,2]$, and assist in the interpretation of the outcomes of diesel engine combustion modelling [3].

In the present work a combination of several optical imaging techniques-flashlight shadowgraphy (SG), laser elastic scattering (LES) and chemiluminescence imaging - were applied quasi-simultaneously, i.e., within a temporal window that is short relative to the characteristic time scales of spray evolution. Experiments were performed in an optically accessible, constant volume high-temperature, high-pressure cell. In addition, laser induced incandescence (LII) was applied to visualize soot in the spray combustion process. Together with its valve-operated inlet and outlet ports this test facility provides measurement conditions that approach a realistic diesel combustion cycle near top dead centre (8 MPa, 520-850 K 
before combustion) with the benefit of reduced complications for optical access to the combustion chamber of real production engines [4-6].

\section{Measurement techniques}

Various optical and laser spectroscopic tools were applied to gather a multitude of complementary information related to the spray propagation and combustion processes. The techniques used in the present study are described briefly below.

Shadowgraphy (SG) experiments [7] image the spray against a uniformly lit background. These images depict regions of a spray that exhibit lower transmittance to a background light source - due to scattering, absorption and deflection of light. Alternatively, in laser elastic scattering (LES) [8] two-dimensional imaging from a region within a thin light sheet is possible in a direction perpendicular to the sheet. In the gas phase, LES provides a two-dimensional image related to the density of the scattering medium. For gas compositions of which the individual species concentrations and respective scattering cross sections are known, temperatures can be evaluated from LES signal intensities, if the latter are calibrated in known environments. After careful calibration, Espey et al. obtained quantitative two-dimensional fuel vapor phase distributions during spray propagation in an optically accessible diesel engine cylinder [9]. With a similar technique Andersson et al. performed quantitative imaging of fuel equivalence ratios in DME sprays introduced into hot atmospheres of a combustion vessel [10]. In laser-induced incandescence (LII) particles (typically in the size range of $1-100 \mathrm{~nm}$ ) are heated close to their vaporization temperature by absorption of radiation from a strong laser pulse and their thermal radiation intensity is recorded in a narrow spectral range during or shortly after the exciting laser pulse. LII is commonly applied for the determination of the local particle volume fraction, such as soot in flames [11-13] and exhaust streams [14]. This information can be inferred from an analysis of the energy and mass balance in the particle ensemble, accounting for absorption of radiation, and cooling by evaporation or sublimation, radiation and heat conduction $[15,16]$. Size distribution measurements are also possible via the temporally resolved LII signal intensity [16-18]. Finally, imaging the spectrally integrated chemiluminescence (CL) intensity (spatially or temporally resolved) from electronically excited species and/or thermal soot radiation provides a global impression of spray ignition, combustion and soot production [19].

\section{3}

3.1

\section{Experimental setup}

\section{High temperature high pressure optical cell}

Figure 1 depicts an outline of the test facility including the constant-volume $(110 \mathrm{~mm}$ high, $40 \mathrm{~mm}$ internal diameter) combustion cell made of a high strength stainless steel alloy, which is optically accessible via four sapphire windows with $40 \mathrm{~mm}$ diameter clear aperture in each side wall. It is equipped with gas intake and exhaust valves and a commonrail fuel injector. This allows the observation of transient liquid

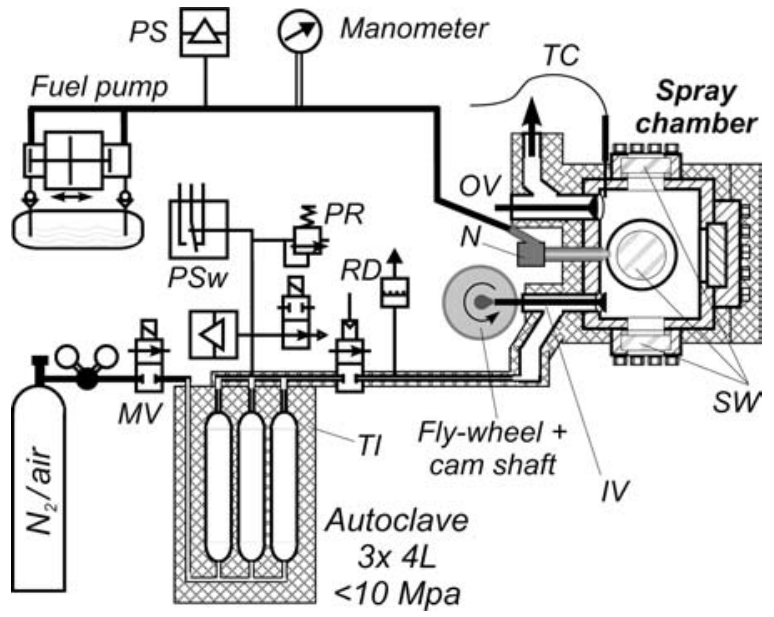

FIGURE 1 Sketch of the test facility employed, including high-temperature high-pressure optical cell and gas/fuel supply system. SW: sapphire window, TI: thermal insulation, IV: inlet valve, OV: exhaust valve, TC: thermocouple, PS: pressure sensor, PSw: pressure switch, MV: magnetic valve, RD: rupture disk, PR: pressure relief valve

fuel injection/combustion events over a broad range of initial gas pressures $(<8 \mathrm{MPa})$ and temperatures $(<850 \mathrm{~K})$ [20-22]. Valve timings and fuel injection can be varied within ranges typical for internal combustion engines, and optical access does not suffer from complications imposed by a moving piston.

The cell can be loaded with compressed gas mixtures, e.g., nitrogen or air, which are pre-heated and pressurized in a 121 autoclave system connected to the inlet port via a pneumatic valve. The whole device is heated electrically by several heating cartridges (cell body: $4 \times 2 \mathrm{~kW}$, connecting gas supply tube: $6 \times 800 \mathrm{~W}$ ) and heating wires (autoclave). Gases are introduced via a cam-shaft driven valve in the inlet port and exhausted through a pneumatically operated valve, respectively, thus simulating a diesel engine combustion cycle without piston movement. A low-aromatic diesel fuel (DEA TT 1420, at atmospheric pressure its end boiling point is approx. located at $360^{\circ} \mathrm{C}$ ) was introduced through a single hole, mini-sac type nozzle (length-to-diameter ratio: 4 , hole diameter: $150 \mu \mathrm{m}$ ) by a fuel injector (Ganser Hydromag AG, Zürich) with electronic valve timing control. The fuel is pressurized with a pneumatically operated piston pump (Heilmeier \& Weinlein, München), which allows injection pressures up to $150 \mathrm{MPa}$. For measurements at higher initial gas temperatures $(850 \mathrm{~K})$ additional heat release was provided through pre-combustion of a pilot fuel injection (nozzle opening time: $4 \mathrm{~ms}) 20 \mathrm{~ms}$ before the main injection event ( $3 \mathrm{~ms}$ duration). A fast pressure sensor (Kistler, mod. 6061B) and a thermocouple $(\mathrm{Ni} / \mathrm{CrNi}, 100 \mu \mathrm{m}$ diameter) were installed close to the fuel injection nozzle in the combustion chamber to record transient events in the gas mixture. Depending on the choice of initial parameters, the operation of a whole experimental cycle (autoclave gas fill, opening of connecting valve for inlet port fill, inlet valve actuation, fuel injection, exhaust valve opening) takes $2-4 \mathrm{~s}$ and is fully under computer control. The injection/combustion cycle is only initiated if the continuously polled temperature and pressure readings from all 


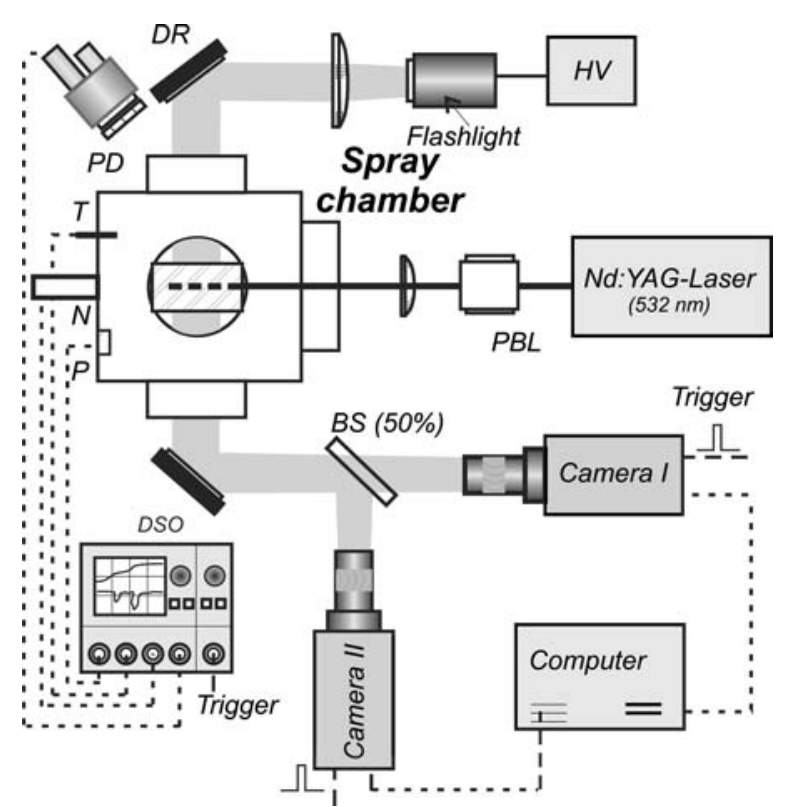

FIGURE 2 Top view of experimental arrangement for multiscalar imaging in the spray combustion cell. Time resolved recording of cell pressure, temperature, chemiluminescence, needle lift and nozzle fuel pressure during a single spray injection/combustion event is done with a photodiode (PD). The laser beam is directed via a prism beam lift (PBL) through the top cell window (in the plane of the figure). BS: beam splitter, DR: diffuse reflector, T, P: temperature, pressure sensor, N: fuel nozzle

relevant parts (cell, nozzle and autoclave) are within preset limits and safe operating ranges.

\section{Optical arrangements}

LES and LII experiments were performed with a frequency-doubled Nd:YAG laser $(532 \mathrm{~nm}, 10 \mathrm{~ns}$ pulsewidth), whereas for shadowgraphy a Xenon flash-lamp (1 $\mu \mathrm{s}$ pulse duration) was used (see Fig. 2). The laser beam was expanded using one cylindrical lens $(f=-30 \mathrm{~mm})$, and subsequently loosely focused by a spherical lens $(f=500 \mathrm{~mm})$ into a thin light sheet ( $0.8 \mathrm{~mm}$ thick) across the full width of the top entrance window of the cell in a plane containing the main spray propagation axis. A 50\% beam splitter allows simultaneous imaging with two intensified CCD-cameras (Dicam-PRO, PCO) through one of the side windows perpendicular to the laser entrance window. Both cameras were equipped with a double-framing option to capture two images within an adjustable delay larger than a minimum of 500 ns necessary for data storage. This allowed the recording of up to four images within less than $1.5 \mu \mathrm{s}$. Compared with the relevant time scales of spray propagation of several $100 \mu \mathrm{s}$, these observations can be considered as instantaneous. A digital delay generator and coincidence trigger unit synchronized the external devices with valve and nozzle injection timing. The prompt LII-signal was detected behind a narrow-band interference filter (centre wavelength $650 \pm 40 \mathrm{~nm}$ ). Spray penetration was evaluated from a series of consecutive images of sequential injections taken with one camera at increasing time delays (in steps of 10 to several $100 \mu \mathrm{s}$ ) after start of injection (SOI). A photodiode coupled to a digital storage oscilloscope recorded spectrally and spatially integrated time-resolved chemiluminescence. Simultaneously, pressure and temperature of the gas as well as the needle lift signal during fuel injection were captured for each injection event.

\section{4}

4.1

\section{Results and discussion}

\section{Non-reacting spray injection}

Spray propagation in high-density gaseous environments without combustion was studied for non-vaporizing and vaporizing conditions by fuel injection into pure nitrogen at temperatures of 520 and $850 \mathrm{~K}$, respectively. SG and LES images for these conditions, a gas pressure of $4 \mathrm{MPa}$ and fuel injection pressure of $100 \mathrm{MPa}$ are shown in Fig. 3. SG and LES images were taken simultaneously with one camera in double framing mode, each with a $100 \mathrm{~ns}$ gate opening time, and firing the Nd:YAG-laser $1 \mu$ s after the Xe flashlight. With a spatial resolution of approximately $0.15 \mathrm{~mm} / \mathrm{pixel}$, and a fluid injection speed of approximately $200 \mathrm{~m} / \mathrm{s}$ this timing sequence ensured the recording of temporally frozen events. For the higher gas temperature (right column in Fig. 3) the image quality is degraded by refractive index variations due to hot air convection in the optical path between cell window and camera objective. From a series of similar recordings at constant environmental conditions but varying delay between SOI and firing of the background flash light penetration and dispersion of the individual spray liquid cores were evaluated.

For the lower temperature case of $520 \mathrm{~K}$, it takes several milliseconds for a droplet to vaporize [23]. In this case the contour lines in the quasi-simultaneous images of spray shadow and laser scattering (left column in Fig. 3) exhibit striking similarities. The outer spray boundary is corrugated due to the presence of turbulent mixing caused by air entrainment and mixing with large scale structures from the liquid core. For vaporizing conditions ( $850 \mathrm{~K}$, right column in Fig. 3) the

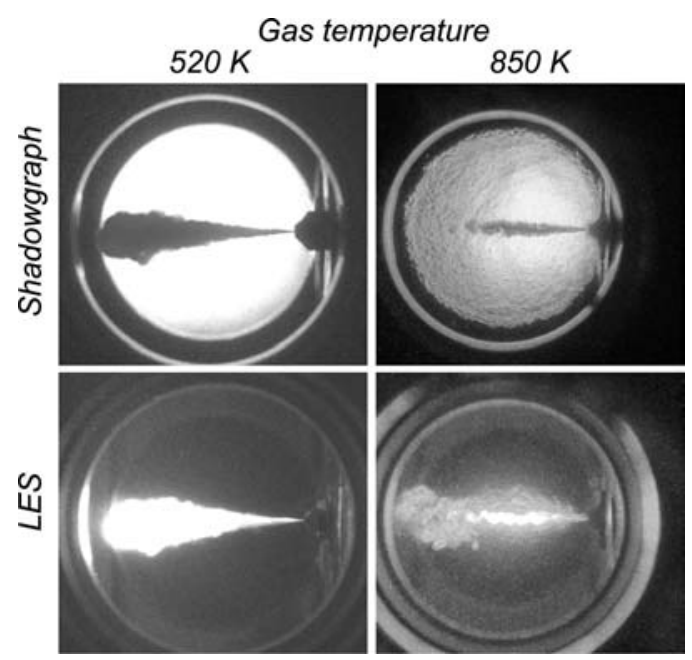

FIGURE 3 Shadowgraph (upper row) and laser scattering images (bottom row) of diesel fuel spray $0.4 \mathrm{~ms}$ after SOI for vaporizing (right column) and non-vaporizing (left column) conditions. At each temperature images in each column were recorded during the same injection event using one camera in double shutter mode, with a gate duration of $100 \mathrm{~ns}$ and a time separation of $1.0 \mu$ s between both exposures. Conditions: $P_{\text {gas }}=4 \mathrm{MPa}$, fuel injection pressure $P_{\text {fuel }}=100 \mathrm{MPa}$ 
SG image shows a relatively short and narrow liquid core region. In the LES image this same spatial area exhibits a high scattering intensity surrounded by areas of lower scattering intensity attributed mostly to vaporized fuel droplets. A clear distinction between fuel vapour and small droplets, however, is not possible with the employed techniques. Since diesel fuel vapour exhibits a much larger Rayleigh scattering cross section than molecular nitrogen from the bulk gas $\left(\sigma_{\mathrm{R}}\right.$ (diesel $) \approx$ $\left.100 \sigma_{\mathrm{R}}\left(\mathrm{N}_{2}\right)\right)$ [24] the recorded scattering intensity also contains contributions from the vapor phase.

Following the analysis of Naber et al. [23], the liquid core region was evaluated by transforming the SG image into a binary image. The penetration length was then defined as the distance between nozzle tip and the downstream tip of the spray cloud projected on the spray propagation axis. A measure of spray dispersion was defined as the cone angle formed between the two lines connecting the spray boundary at half the penetration depth with the cone origin at the nozzle exit.

Examples of penetration length $S(t)$ (squares) and dispersion curves $\theta(t)$ (triangles) for vaporizing (open symbols) and non-vaporizing (solid symbols) conditions are presented in Fig. 4. In the dispersion curve the spray angle first increases to a maximum, which is located slightly before the spray break-up time (see Eqs. 2, 6 below). For the lower temperature investigated, the curve slowly declines again and remains fairly constant throughout the investigated propagation duration, as is also shown by the data taken at higher temperature. For a nozzle diameter similar to ours $(0.198 \mathrm{~mm}$ instead of $0.150 \mathrm{~mm})$ and a fuel pressure of $110 \mathrm{MPa}$ Naber et al. [23] give a correlation between dispersion angle and the ratio of ambient to fuel densities of $\tan (\theta / 2)=0.31\left(\rho_{\mathrm{a}} / \rho_{\mathrm{f}}\right)^{0.19}$, from which a steadystate angle of $\theta=21^{\circ}$ can be calculated for a gas temperature of $500 \mathrm{~K}$. The apparent discrepancy to our experiment (approx. $14^{\circ}$ opening angle, see Fig. 4) is not surprising owing to the different nozzle hole diameter (33\% larger than ours) and fuel type employed in their experiments. It is also known that the geometric shape of nozzles has a pronounced effect on spray characteristics [25].

The experimental data were correlated with semiempirical spray penetration models [2, 23] developed for scal-

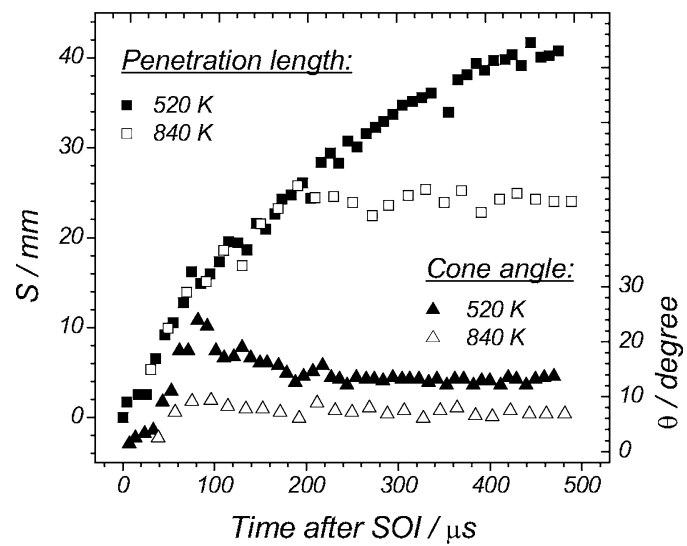

FIGURE 4 Spray penetration length $S(t)$ (squares) and dispersion angle $\theta(t)$ (triangles) as a function of time after Start of Injection, obtained for a chamber pressure of $6 \mathrm{MPa}$ and temperatures of $520 \mathrm{~K}$ and $840 \mathrm{~K}$, respectively. $P_{\text {fuel }}=100 \mathrm{MPa}$ ing the propagation characteristics for a number of different fuel types and a variety of environmental conditions and nozzle shapes. In general, propagation of a non-vaporizing fuel spray in a dense gaseous environment can be subdivided into four regimes [25]: (a) the 'opening transient', which is governed by the needle tip movement with a corresponding time dependent effective orifice opening area; (b) the propagation of the liquid core into the surrounding atmosphere; (c) the droplet break-up stage, and (d) propagation of the droplet clouds. According to the model of Hiroyasu et al. [2] experimental data points for penetration length in double logarithmic plots should fall approximately on straight lines in the range of propagation phases (b) and (d). Beyond the transient opening phase this model predicts an initial linear increase with time of the spray penetration length $S_{\mathrm{H}}(t \rightarrow 0)$ :

$S_{\mathrm{H}}(t \rightarrow 0)=0.39 \sqrt{\frac{P_{\mathrm{f}}-P_{\mathrm{a}}}{\rho_{\mathrm{f}}}} t$

After a 'breakup time' of

$t_{\mathrm{b}, \mathrm{H}}=28.7 \frac{d_{0} \sqrt{\tilde{\rho}}}{\sqrt{\left(P_{\mathrm{f}}-P_{\mathrm{a}}\right) / \rho_{\mathrm{f}}}}$,

for long times after SOI a square-root time dependence according to

$S_{\mathrm{H}}(t \rightarrow \infty)=2.95 \sqrt{\sqrt{\frac{P_{\mathrm{f}}-P_{\mathrm{a}}}{\rho_{\mathrm{a}}}} d_{0} t}$

is expected. Here, $d_{0}$ denotes the geometric nozzle hole diameter, and $\tilde{\rho}=\rho_{\mathrm{f}} / \rho_{\mathrm{a}}$ the dimensionless density ratio of fuel and ambient air with pressures $P_{\mathrm{f}}$ and $P_{\mathrm{a}}$, respectively.

Alternatively, the model of Naber et al. [23] can be applied to a large variety of fuel types and environmental parameters. In dimensionless form the time $\tilde{t}$ to reach a penetration depth $\tilde{S}$ is given by

$\tilde{t}=\frac{\tilde{S}}{2}+\frac{\tilde{S}}{4} \sqrt{1+16 \tilde{S}^{2}}+\frac{1}{16} \ln \left(4 \tilde{S}+\sqrt{1+16 \tilde{S}^{2}}\right)$

where $d_{\mathrm{f}}=\sqrt{C_{\mathrm{a}}} d_{0}$ is the diameter of the liquid fuel jet at the nozzle exit, and

$U_{\mathrm{f}}=C_{\mathrm{v}} \sqrt{2 \frac{P_{\mathrm{f}}-P_{\mathrm{a}}}{\rho_{\mathrm{f}}}}$

its exit velocity. Furthermore, $C_{\mathrm{a}}$ is the area contraction coefficient, and $C_{\mathrm{v}}$ a velocity coefficient through which a discharge coefficient $C_{\mathrm{d}}=C_{\mathrm{a}} C_{\mathrm{v}}$ is defined. This considers the fluid flow restriction through the valve orifice opening area during retraction of the needle from its seat. Length and time in Eq. 4 are scaled into dimensionless form using $d_{\mathrm{f}}, \tilde{\rho}, \theta$ and $U_{\mathrm{f}}$ (for a full derivation see [23]). Naber et al. define their 'breakup time' $t_{\mathrm{b}, \mathrm{N}}$ as the 'transition time' where $\tilde{t}=1$, which leads to:

$t_{\mathrm{b}, \mathrm{N}}=\frac{\sqrt{C_{\mathrm{a}} / 2}}{C_{\mathrm{v}} a \tan (\theta)} \frac{d_{0} \sqrt{\tilde{\rho}}}{\sqrt{\left(P_{\mathrm{f}}-P_{\mathrm{a}}\right) / \rho_{\mathrm{f}}}}$

In Fig. 5 the measured $S(t)$ data (symbols) for a particular experiment in the non-vaporizing case $\left(T_{\mathrm{a}}=520 \mathrm{~K}\right.$, $P_{\mathrm{f}}=100 \mathrm{MPa}, P_{\mathrm{a}}=4 \mathrm{MPa}$ ) are plotted together with results 


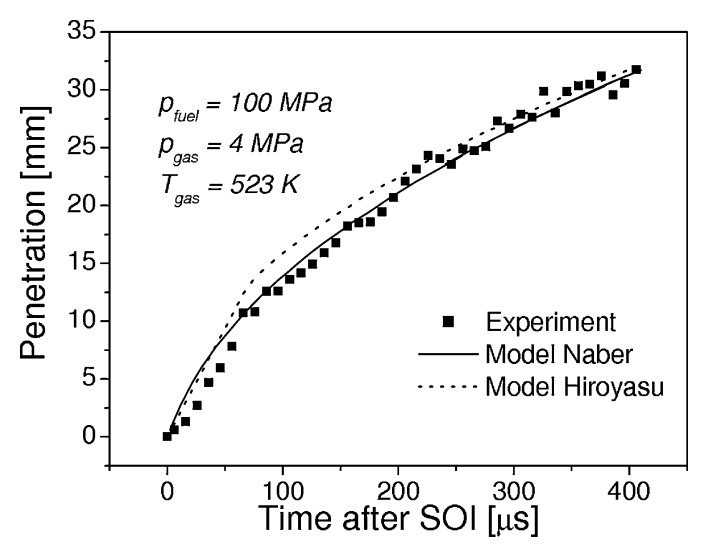

FIGURE 5 Experimental (squares) penetration curve together with model predictions from Hiroyasu [2] (dashed line) and Naber et al. [23] (solid line). $P_{\text {fuel }}=100 \mathrm{MPa}, P_{\text {gas }}=4 \mathrm{MPa}, T_{\text {gas }}=520 \mathrm{~K}$

from both models above. For our conditions a discharge coefficient of 0.4 and a break-up time of $20 \mu$ s were derived from the Naber et al. model, whereas the Hiroyasu model predicts a $t_{\mathrm{b}, \mathrm{H}}$ of $66 \mu \mathrm{s}$, which corresponds to a breakup length of roughly $12 \mathrm{~mm}$. As is outlined in [23] Eqs. 2 and 6 reveal that the Hiroyasu break-up times are a factor of 3.7 larger than those calculated in the Naber et al. model. Our data more closely follow the Naber model, although it overestimates penetration lengths at short injection times, probably due to the rather slow opening times realized in our nozzle. Also the opening transient of our nozzle obviously does not allow a clear distinction of the initial spray penetration behavior described above.

Similar to findings in $[2,23]$, for vaporizing conditions at higher gas temperatures $\left(T_{\mathrm{a}}>750 \mathrm{~K}\right.$, i.e., above the boiling point of the fuel) we observe the liquid core penetration to cease and dispersion to decrease, i.e., the spray liquid length stays constant with time and exhibits a smaller cone angle (see Fig. 4). In addition, the LES images indicate a vapour cloud around and far beyond the liquid jet (see Fig. 3).

\section{2}

\section{Reacting sprays}

4.2.1 Spray penetration, fuel/air mixing and auto ignition. Combustion was initiated in the cell through self-ignition of the injected fuel spray in air loads of given temperature and pressure. Panels $c$ and $e$ in Fig. 6 display the respective temporal history of pressure and temperature for an experiment performed during combustion of a pilot and main diesel injection with initial air pressure and temperature of $3.2 \mathrm{MPa}$ and $850 \mathrm{~K}$, respectively, and an injection pressure of $100 \mathrm{MPa}$. Nozzle opening durations for pilot $(3.5 \mathrm{~ms})$ and main $(4 \mathrm{~ms})$ injection event can approximately be deduced from the simultaneously recorded signals of the needle lift sensor or the pressure sensor in the fuel line (traces $a$ and $b$ in Fig. 6, respectively). The thermocouple bead is located $20 \mathrm{~mm}$ next to the nozzle tip and protrudes $15 \mathrm{~mm}$ into the gas. Therefore, its reading is not representative for the temperature near the core of the spray, but rather an indication of a global gas temperature before injections and after combustion gases have mixed

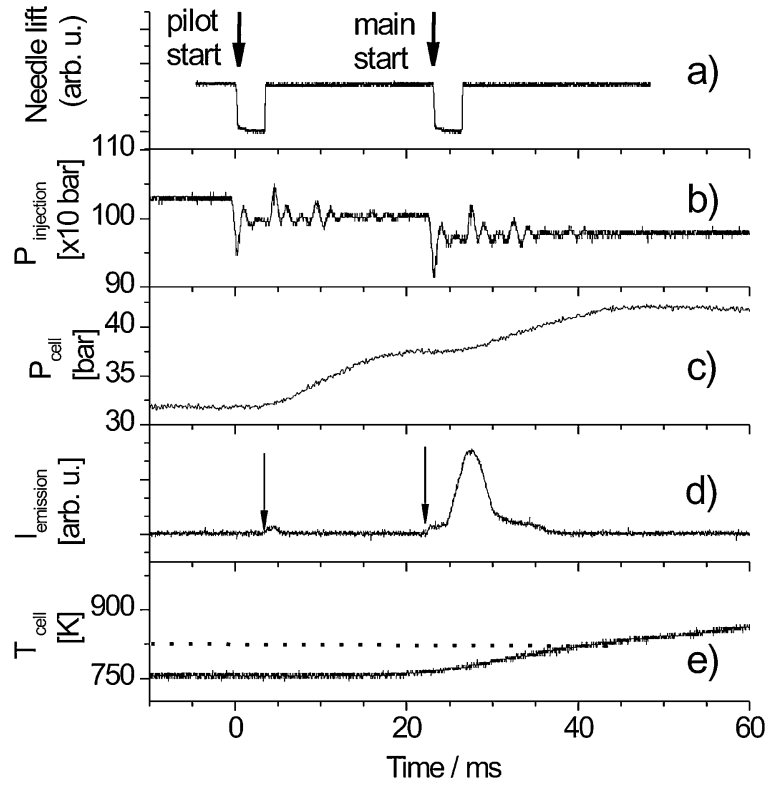

FIGURE 6 Simultaneous recording of the needle lift signal, rail pressure, gas pressure, chemiluminescence and gas temperature (panels a-e, respectively) in the combustion vessel during a single spray injection/combustion cycle. The arrows in panel $\mathbf{d}$ mark the start of ignition after pilot and main injection, which approximately takes place at a gas temperature of $850 \mathrm{~K}$ (horizontal dotted line in panel e). Injection duration: $3.5 \mathrm{~ms}$ (pilot), $4 \mathrm{~ms}$ (main). $P_{\text {gas }}=3.2 \mathrm{MPa}, P_{\text {fuel }}=100 \mathrm{MPa}$

with the residual gas in the chamber. Trace $d$ shows the chemiluminescence intensity recorded with the photodiode. The arrows above the chemiluminescence trace mark the beginning of the first detectable emission signals after injections following the respective pressure drop in the fuel line. The auto ignition delay times for pilot and main injection of $(3.15 \pm 0.10)$ $\mathrm{ms}$ and $(0.36 \pm 0.06) \mathrm{ms}$, respectively, were derived from the time delays between pressure or needle lift indicators and the first appearance of chemiluminescence emission. Placing a uv-transmitting filter in front of the detector qualitatively revealed radiation emitted during the pilot injection phase to be almost entirely due to flame emission. The rather long auto ignition delay for the pilot injection is due to the low initial gas temperature. The CL trace, although changing in shape and intensity from one cycle to the other, qualitatively exhibits the displayed temporal characteristic of a two-stage intensity during the main injection event. Although no spectral filtering of the detected radiation was performed we attribute the initial small rise of the emission intensity to first flame emission, i.e., radical species; the large peak later in the light emission profile during main injection indicates thermal soot radiation (see below).

Typical images recorded around $0.5 \mathrm{~ms}$ after SOI are shown in Fig. 7. In these experiments fuel was injected into $4 \mathrm{MPa}$ of air at $780 \mathrm{~K}$, additionally heated to approximately $850 \mathrm{~K}$ by the pilot combustion event. Progress of the main fuel injection was systematically studied by applying shadowgraphy. The set of SG, LES and CL images depicted in Fig. 7 was recorded quasi-simultaneously with two cameras. Within the first gate opening time camera 1 captured the SG image during the peak of the Xe-flashlight, while the CL image was recorded $1 \mu$ s later during the second gate opening ("double 


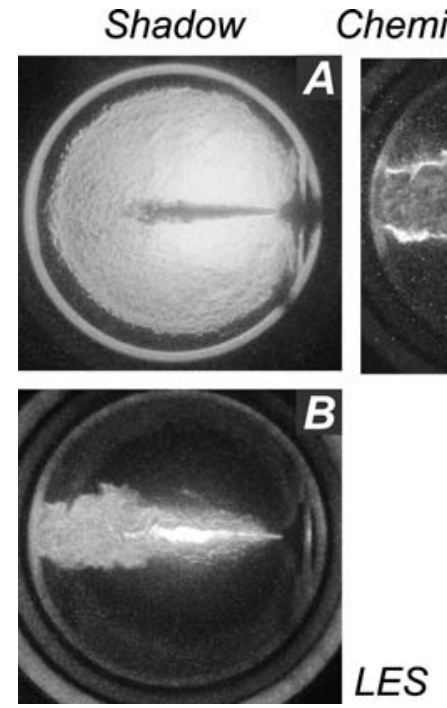

FIGURE 7 Shadowgraphy, laser elastic scattering (LES) and chemiluminescence images (from $\mathbf{A}$ to $\mathbf{C}$ ) recorded quasi-simultaneously with two cameras. Camera 1 was triggered at the time of the Xe-flashlight peak, and captured the shadowgraph image $\mathbf{A}$ during the first gate opening time, while the chemiluminescence signal was registered during a second exposure $1 \mu$ s after this event $\mathbf{C}$. Recording of the LES image $\mathbf{B}$ was accomplished with camera 2 triggered at the time of the Nd:YAG laser firing. Reacting spray conditions $0.5 \mathrm{~ms}$ after start of main injection event. Initial conditions: $T_{\text {gas }}=850 \mathrm{~K}$, $P_{\text {gas }}=4 \mathrm{MPa}, P_{\text {fuel }}=103 \mathrm{MPa}$, pilot injection duration: $3 \mathrm{~ms}$, main injection duration: $2 \mathrm{~ms}, 20 \mathrm{~ms}$ after pilot injection

framing option"). Camera 2 was triggered in between these two events to record the $532 \mathrm{~nm}$ filtered LES image induced by the firing Nd:YAG laser. During this stage of combustion there was no evidence of soot formation, i.e., the emission features mainly originate from radical chemistry [19]. A series of similar images taken at different delay times from SOI (not shown) indicated that the full liquid jet length of $\sim 24 \mathrm{~mm}$ was rapidly built up during the first $\sim 0.2 \mathrm{~ms}$ and remained fairly constant for the rest of the injection duration (cf. Fig. 4). At $850 \mathrm{~K}$ temperature is high enough for a significant fraction of the fuel to be transferred to the vapor phase at the time after SOI the image (panel $B$ ) was taken, and the LES may be dominated by a vapour cloud at the tip region and surrounding the liquid core upstream, even close to the nozzle exit. Combustion-related CL emission occurs over the downstream portion of the vapour cloud, mainly from within the mixing layer between fuel vapour and surrounding air. Inspection of the LES and the CL images in Fig. 7 (panels $B, C$, respectively) suggests that ignition takes place along the rim of the vapour cloud establishing a diffusion or partially premixed flame. This early, relatively weak radiation can be ascribed to exothermic chemical reactions [26] (note: the images were taken before the onset of soot radiation displayed in Fig. 6, trace d, as the large CL peak after main fuel injection). Although caution is appropriate in interpreting experimental results, spectrally selected chemiluminescence emissions from intermediate species give some indication for the spatial location of initial heat release due to combustion $[27,28]$. After the start of intense soot incandescence the order of magnitude larger radiation intensity will hamper this interpretation.
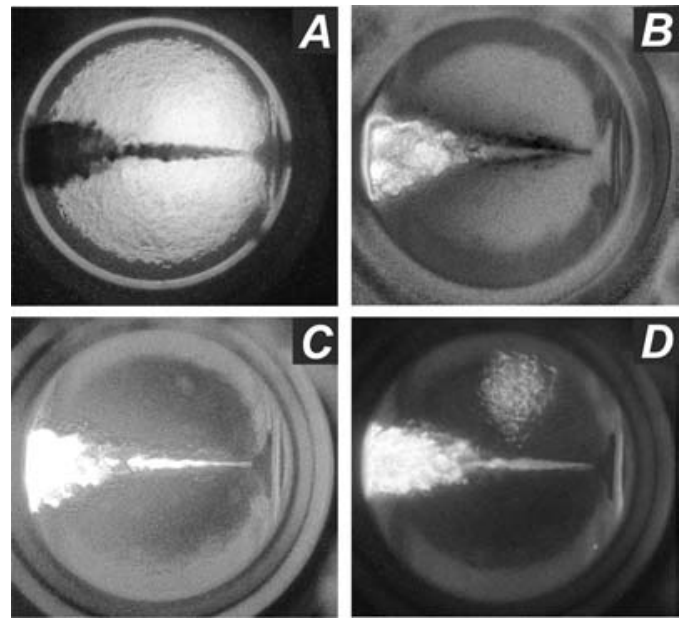

FIGURE 8 Shadowgraph A, chemiluminescence B, laser elastic scattering C, and LII D images obtained at $\sim 1 \mathrm{~ms}$ after SOI. Same conditions as in Fig. 7. Images $\mathrm{A}$ and $\mathrm{B}$ were recorded with camera 1 (with intensifier gates separated by $1 \mu \mathrm{s}$ ), while image $\mathrm{C}$ was taken with camera 2 through a $532 \mathrm{~nm}$ interference filter. Image D was captured with camera 2 (equipped with the $650 \mathrm{~nm}$ interference filter) on a separate injection event at otherwise identical conditions

4.2.2 Premixed combustion and soot formation regions. Following the conceptual model of Dec for spray combustion in a DI diesel engine [1] the initial soot formation region is situated near the tip of the fuel-rich, premixed reaction zone of the vaporized liquid spray core. In our experiments such a zone is identified approximately around $0.7 \mathrm{~ms}$ after SOI, when SG, LES and CL images indicate changes in the spray combustion event: the shadowgraphs reveal the appearance of opaque regions within the luminous combustion zone. Simultaneously, spatial regions exhibiting strong light scattering and thermal soot radiation in the respective LES and CL images provide evidence of soot formation. Soot particle concentration and size continue to increase with combustion progress and are accumulating in the leading portion of the jet boundaries [1,29]. This combustion stage is accompanied by a sharp increase of the CL signal intensity recorded by the photodiode (trace $d$ in Fig. 6).

Images recorded even later in the combustion cycle $(1 \mathrm{~ms}$ after SOI) are shown in Fig. 8. Shadow and chemiluminescence images (panels $A, B$ in Fig. 8, respectively) were recorded with camera 1 (with gate opening times separated by $1 \mu \mathrm{s}$ ), while the LES image $(C)$ was captured with camera 2 through the $532 \mathrm{~nm}$ interference filter. The LII image $(D)$ was recorded from a separate injection event at the same delay after SOI. Because the LII image required filter exchange in front of the camera lens, in the current setup a quasi-simultaneous recording with the other images was not possible. The shadowgraph image indicates a dense, narrow liquid spray core and a spatially more spread out cloud downstream where soot is formed. This is also evident from the chemiluminescence image, which essentially is dominated by thermal soot radiation. The LES image $(C)$ again shows a close correspondence with the SG image in the soot-loaded as well as the liquid core region of the spray. Finally, the LII-image $(D)$ also demonstrates the existence of an extensive soot formation region downstream of the spray tip. (we attribute the visible faint "pencil-like" structure extending from the nozzle tip to 
(laser-induced) soot radiation scattered off fuel droplets in the spray. It is important to note that the SG- and CL-images represent line-of-sight views from within the focused object space determined by the aperture and transfer function of the camera objective, whereas images $C$ and $D$ are two-dimensional cross sections of the spray/soot cloud spatially integrated within the the laser sheet thickness (approx. $0.8 \mathrm{~mm}$ ). Nevertheless, all three images taken simultaneously exhibit quite similar spatial features, and they clearly identify soot formation regions in the combusting vapour cloud downstream of the dense spray region.

\section{5}

\section{Conclusions}

A constant volume combustion bomb was constructed suitable for detailed optical diagnostics of diesel fuel spray injection, propagation and ignition in high-density gaseous environments $(T<850 \mathrm{~K}, P<8 \mathrm{MPa})$. Inert gas or air is introduced into the cell through a cam-shaft actuated inlet valve prior to diesel fuel injection. Pre-combustion of a piloted fuel injection allowed a short-term temperature increase of the pressurized and preheated gas load prior to the main injection event. As a novelty, quasi-simultaneous imaging of spray propagation and combustion was performed using two ICCD-cameras with double framing options. Twodimensional flash-light shadowgraphy, laser elastic scattering and chemiluminescence were applied to investigate various phases of fuel propagation and combustion after start of injection. In addition, soot formation was investigated with laser-induced incandescence. From the results presented in this paper, the following conclusions can be drawn:

- The combination of shadowgraphy and laser elastic scattering shows that before spray break-up the shape of the dense liquid phase region of the spray is similar in the non-reacting as well as the reacting environment.

- At $4 \mathrm{MPa}$ and temperatures below $550 \mathrm{~K}$ the combination of shadowgraphy and laser elastic scattering indicate that liquid fuel droplets still exist up to a penetration length of at least $40 \mathrm{~mm}$ (length/diameter ratio $=67$, limited by the optical window field of view). Penetration lengths and angle dispersion match with scaling predictions from the literature.

- In the combusting spray the combination of laser elastic scattering, shadowgraphy, chemiluminescence emission and LII indicate initial soot formation near the tip of the spray cloud.

In conclusion, our spray combustion cell allows the study of multiphase flows and combustion of sprays within parameter ranges relevant in diesel engines. The quantitative evaluation of LII image data and time-resolved LII signal intensities, i.e., the determination of soot volume fraction and mean particle size, will be future tasks in the research work performed with the optical cell [30]. Further efforts have to be directed towards improved image spatial resolution and the statistical evaluation of image data.

ACKNOWLEDGEMENTS The financial support of the Swiss Federal Office of Energy and the Technology Foundation STW in the Netherlands, as well as the technical expertise of P. Obrecht (ETH Zentrum, Zürich) during installation and initial operation of the test cell facility are gratefully acknowledged.

\section{REFERENCES}

1 J.E. Dec, SAE Tech. Pap. Series No. 970873, 1 (1997)

2 H. Hiroyasu, M. Arai, Transactions of the SAE 99, 1050 (1990)

3 P.F. Flynn, R.P. Durrett, G.L. Hunter, A.O. zur Loye, O.C. Akinyemi, J.E. Dec, C.K. Westbrook: SAE Tech. Pap. Series No. 1999-01-0509 (1999)

4 J.E. Dec, E.B. Coy, SAE Tech. Pap. Series No. 960831 (1996)

5 F. Hildenbrand, C. Schulz, Appl. Phys. B 73, 173 (2001)

6 H. Kubach, J. Gindele, U. Spicher, SAE Tech. Pap. Series No. 2001-013647 (2001)

7 G.S. Settles, Schlieren and Shadowgraph Techniques (Springer Berlin Heidelberg New York, 1964)

8 A.C. Eckbreth, Laser Diagnostics for Combustion, Temperature and Species (Taylor \& Francis Inc., London, 1996)

9 C. Espey, J.E. Dec, T.A. Litzinger, D.A. Santavicca, Comb. \& Flame 109, 65 (1997)

10 Ö. Andersson, R. Collin, M. Aldén, R. Egnell, SAE Tech. Pap. Series No. 2000-01-2785 (2000)

11 H. Zhao, N. Ladommatos, Progr. En. Combust. Sci. 24, 221 (1998)

12 K. Kohse-Höinghaus, J. Jeffries (eds.): Applied Combustion Diagnostics (Taylor \& Francis Inc., Cambridge, 2002)

13 P.O. Witze, S. Hochgreb, D. Kayes, H.A. Michelsen, C.R. Shaddix, Appl. Opt. 40, 2443 (2001)

14 D.R. Snelling, G.J. Smallwood, R.A. Sawchuk, W.S. Neill, D. Gareau, D. Clavel, W.L. Chippior, F. Liu, Ö.L. Gülder, W.D. Bachalo, SAE Tech. Pap. Series No. 1999-01-3653 (1999)

15 L.L.A. Melton, Appl. Opt. 23, 2201 (1984)

16 B.F. Kock, P. Roth, in Proceeding of the Europian Combustion Meeting (2003)

17 T. Lehre, B. Jungfleisch, R. Suntz, H. Bockhorn, Appl. Opt. 42, 2021 (2003)

18 P. Roth, A.V. Filippov, J. Aerosol Sci. 27, 95 (1996)

19 A.G. Gaydon, H.G. Wolfhard, Flames (Chapman \& Hall, London, 1979)

20 P. Obrecht, T. Gerber, A.P. Tzannis, B. Mischler, P.P. Radi, H.-M. Frey, P. Beaud, PSI Report 1997 V, 56 (1998)

21 B. Schneider, Experimentelle Untersuchungen zur Spraystruktur in transienten verdampfenden und nicht verdampfenden Brennstoffstrahlen unter Hochdruck. DISS ETH Nr. 15004, ETH, Zürich (2003). Internet: http://e-collection.ethbib.ethz.ch/browse/alph/s.html

22 G. Barroso, B. Schneider, K. Boulouchos, SAE paper, nr. 03FFL-190 (2003)

23 J.D. Naber, D.L. Siebers, SAE Technical Paper Series No. 960034 (1996)

24 A.I. Vogel, J. Chem. Soc. 9, 133 (1946)

25 A. Lefebvre, Atomization and Sprays (Hemisphere Publishing Comp, New York, 1989)

26 Y. Ohta and M. Furutani, Archivum Combustionis 11, 43 (Polish Academy of Sciences, 1991)

27 H.N. Najm, P.H. Paul, C.J. Mueller, P.S. Wyckhoff, Comb. Flame 113, 312 (1998).

28 Y. Hardalupas, M. Orain, Comb. Flame 139, 188 (2004)

29 C. Crua, D.A. Kennaird, M.R. Heikal, Comb. Flame 135, 475 (2003)

30 H. Bockhorn, H. Geitlinger, B. Jungfleisch, T. Lehre, A. Schön, T. Streibel, R. Suntz, PCCP 4, 3780 (2002) 